\title{
Graft Duodenal Perforation due to Internal Hernia after Simultaneous Pancreas-Kidney Transplantation: Report of a Case
}

\author{
Yuichi Fumimoto ${ }^{\mathrm{a}}$ Masahiro Tanemura $^{\mathrm{a}}$ \\ Yoshihiko Hoshida $^{\mathrm{b}}$ Toshirou Nishida $^{\mathrm{a}}$ Yoshiki Sawa $^{\mathrm{a}}$ \\ Toshinori Itoc
}

Departments of aSurgery (E1), ${ }^{b}$ Pathology and ${ }^{~}$ Complementary and Alternative

Medicine, Osaka University Graduate School of Medicine, Suita, Japan

\section{Key Words}

Type I diabetes mellitus - Pancreas transplantation · Intraabdominal infection · Graft duodenal perforation - Graft pancreatectomy

\begin{abstract}
Although complications including graft thrombosis, graft pancreatitis, and rejection have been well documented after pancreas transplantation, the occurrence of graft duodenal perforation is uncommon. In this article, we report a case of graft duodenal perforation due to internal hernia after simultaneous pancreas-kidney transplantation (SPK). A patient with type I diabetes mellitus and diabetic nephropathy had undergone SPK from a cadaveric donor. One year later, she was admitted to our hospital for severe lower abdominal pain with preshock status. She was immediately examined by abdominal computed tomography and both peripancreas graft fluid accumulation and severe dilatation of the ileum were detected. On emergency operation, two punched holes located at the graft duodenal side near the suture line and an obstruction of herniated bowel behind the graft pancreas were detected. These holes were repaired and the internal hernia was reduced. However, a control of the intraabdominal infection was very difficult despite intensive treatment with antibiotics and additional abdominal drainage. Finally, a graft pancreatectomy was unavoidably required. When complications, including symptomatic intraabdominal infection, require re-laparotomy after pancreas transplantation, the therapeutic focus should be switched from salvaging the graft to the preservation of life.
\end{abstract}




\section{Introduction}

Type I diabetes mellitus is a particularly challenging disease, because the establishment of euglycemic status is quite difficult despite advances in medical treatment. The outcomes of pancreas transplantation have improved progressively because of the recent advances both in surgical techniques and immunosuppressive reagents. As a result, pancreas transplantation is an established therapy to cure patients with type I diabetes mellitus and can improve life span as well as quality of life [1,2]. However, pancreas transplantation is still associated with relatively higher surgical complication rates than other routinely performed solid organ transplantations [3,4]. Although complications including graft thrombosis, graft pancreatitis, and rejection have been well documented after pancreas transplantation, the occurrence of graft duodenal perforation is uncommon. In this article, we report a case of graft duodenal perforation due to internal hernia after simultaneous pancreas-kidney transplantation (SPK).

\section{Case Report}

The patient was a 35-year-old female who had a long history of type I diabetes mellitus for 24 years. She was on hemodialysis for diabetic nephropathy since the age of 29 . SPK was performed from a cadaveric donor in October 2003. The cold ischemic time was $11 \mathrm{~h} 20 \mathrm{~min}$. The graft duodenum and pancreas were adequately perfused without any abnormal findings including ischemic changes. Enteric drainage was adopted with a side-to-side anastomosis between the ileum and the graft duodenum. She received tacrolimus-based immunosuppressive therapy, including basiliximab, predonisolone and mycophenolate mofetil. She was free from hemodialysis and from insulin therapy on day 4 after SPK. She was discharged on day 37 posttransplantation.

In November 2004, the right lower abdominal pain occurred and gradually increased. She was admitted to our hospital because of severe lower abdominal pain with preshock status two days later. Abdominal computed tomography $(\mathrm{CT})$ revealed fluid accumulation in the space of perigraft pancreas and severe dilatation of the total ileum (fig. 1). An emergency laparotomy was performed. The operative findings revealed two punched holes located near the suture line at the graft duodenum and a small bowel obstruction secondary to the herniation of the ileum behind the graft pancreas. We subsequently repositioned this herniated ileum, performed direct closure of the punched holes and put a loop ileostomy.

On day 5 after the emergency operation, she again developed abdominal pain and fever. A recurrent large intraabdominal abscess in the right flank was revealed by abdominal ultrasonography and CT. This recurrent abscess was subsequently drained percutaneously. However, abdominal CT detected separate intraabdominal abscesses again after the abdominal drainage. On postoperative day 10, a re-laparotomy was performed. Abscess formations were found in some spaces, but the pancreas graft itself fortunately appeared normal. Furthermore, no leakage of pancreatic juice at the graft duodenum, in which surgical repair had been performed, was observed. Accordingly, we decided to perform abdominal drainage with preserving graft pancreas. However, a reelevation in fever was observed despite the abdominal drainage. A contrast study using ileostomy showed large amounts of leakage at the graft duodenum which indicated reperforation. In the second look operation, we concluded that the repair of the holes at the graft duodenum was intractable from the macroscopical findings. To save her life, we finally decided to perform a graft pancreatectomy on postoperative day 16 . As shown in figure 2, two holes were observed at the graft duodenum along the suture line in the resected specimen. Microscopic findings of the graft duodenum showed edematous mucosa and lymphocyte infiltration. Ischemic change, chronic rejection and cytomegalovirus were not histologically found in the graft duodenal wall. The excised graft pancreas revealed that pancreatic islets and the exocrine glands appeared to be nearly intact. After the graft pancreatectomy, she recovered immediately from the severe infectious status. At present, she is followed up in our outpatient clinic with insulin therapy and is on the waiting list for pancreas transplantation. 


\section{Discussion}

SPK can be considered the only life-saving treatment for uremic diabetic recipients [ 1 , 2]. The outcomes of pancreas transplantation have improved progressively because of the recent advances both in surgical techniques and immunosuppressive reagents.

Nevertheless, this procedure has relatively higher surgical complication rates than other routinely performed whole organ transplantations [3,4]. In particular, intraabdominal infection, which has been reported in around $20 \%$ of cases, is a well-described complication of whole organ pancreas transplantation, resulting in patient morbidity and loss of the graft pancreas [3].

According to the International Pancreas Transplant Registry (IPTR), although the surgical complications including thrombosis, infection, pancreatitis, anastomotic leak and bleeding were the major causes of the graft failure in the first 6 months after transplantation $(>55 \%)$, those complications decreased $(<10 \%)$, but the immunological complications including chronic rejection increased 12 months posttransplant. In a recent report, Colling et al. studied graft pancreas survival in 163 SPK cases [5]. Many early ( $<6$ months) graft failures can be attributed to thrombosis of either an artery or a vein in 6 of $9(67 \%)$ early events. On the other hand, chronic rejection is a major contributor to late (>6 months) graft pancreas failures in 18 of 27 (67\%) late events. Late pancreas graft failure due to graft duodenal perforation is unique. As shown in table 1, only six cases of graft duodenal perforation after pancreas transplantation, including our case, have been reported in the literature [6-10]. In their case reports, the causes of graft duodenal perforation were rejection, cytomegalovirus duodenitis and simple ulcer. In our case, no ischemic change and no chronic rejection were found histologically in the graft duodenum. Thus, we speculated that this graft duodenal perforation occurred due to the following reason: the intraluminal pressure of the terminal ileum was suddenly increased by obstructive ileus due to internal hernia. Additionally, the fiber-rich food residue passing through the anastomosis may significantly affect this perforation and intraabdominal infection. Thereafter, we decided to adopt Roux-en-Y reconstruction as enteric drainage after this case. If this reconstruction is performed, the anostomotic region of the graft duodenum has no adverse influences of food residues. Furthermore, the anastomosis of the intestinal tract is unnecessary when we are obliged to performed graft pancreatectomy.

Gruessner et al. reported that re-laparotomy was totally required in $32 \%$ of pancreas transplantations and that the common indications were as follows: intraabdominal infection, vascular graft thrombosis, anastomotic leaks including duodenal stumps, and uncontrollable bleeding [3]. At first, we tried to preserve the graft pancreas because it appeared to be almost intact in the operative findings and the blood sugar level was well controlled. However, a total of three re-laparotomies were eventually required to cure the intraabdominal infection, and finally we were obliged to perform a graft pancreatectomy. Pancreatic transplant recipients are always susceptible to bacterial or fungal infections under immunosuppression despite intensive therapy with antibiotics and with abscess drainage. It was reported that of all intraabdominal infections after pancreas transplantation, a transplant pancreatectomy was performed in $70 \%$ of recipients [3].

Accordingly, we conclud that the therapeutic focus should be switched from graft salvage to life saving in a case of symptomatic intraabdominal infection requiring re-laparotomy. Furthermore, drainage should be performed in a timely manner, and treatment and re-laparotomy should be performed expeditiously. These cornerstones of therapy should improve the prognosis after pancreas transplantation. 
Table 1. Reported cases of graft duodenal perforation after pancreas transplantation

\begin{tabular}{|c|c|c|c|c|c|c|c|}
\hline References & $\begin{array}{l}\text { Age/ } \\
\text { gender }\end{array}$ & $\begin{array}{l}\text { Chief } \\
\text { com- } \\
\text { plaint }\end{array}$ & $\begin{array}{l}\text { Pancreas } \\
\text { transplant } \\
\text { category }\end{array}$ & Drainage & $\begin{array}{l}\text { Cause of } \\
\text { graft duodenal } \\
\text { perforation }\end{array}$ & $\begin{array}{l}\text { Interval from } \\
\text { transplantation } \\
\text { to graft duo- } \\
\text { denal per- } \\
\text { foration }\end{array}$ & Operation \\
\hline $\begin{array}{l}\text { Gruessner } \\
\text { et al. [6] }\end{array}$ & $\begin{array}{l}30 \text { years } \\
\mathrm{M}\end{array}$ & $\begin{array}{l}\text { abdominal } \\
\text { pain }\end{array}$ & PTA & enteric & rejection & 27 months & $\begin{array}{l}\text { graft } \\
\text { duodenectomy }\end{array}$ \\
\hline $\begin{array}{l}\text { Schleibner } \\
\text { et al. [7] }\end{array}$ & $\begin{array}{l}33 \text { years } \\
M\end{array}$ & $\begin{array}{l}\text { abdominal } \\
\text { pain }\end{array}$ & SPK & bladder & simple ulcer & 5 months & $\begin{array}{l}\text { direct } \\
\text { closure }\end{array}$ \\
\hline $\begin{array}{l}\text { Stephanian } \\
\text { et al. [8] }\end{array}$ & $\begin{array}{l}32 \text { years } \\
\mathrm{F}\end{array}$ & $\begin{array}{l}\text { abdominal } \\
\text { pain }\end{array}$ & PTA & bladder & $\begin{array}{l}\text { cytomegalovirus } \\
\text { duodenitis }\end{array}$ & 18 months & $\begin{array}{l}\text { graft } \\
\text { duodenectomy }\end{array}$ \\
\hline $\begin{array}{l}\text { Esterl et al. } \\
\text { [9] }\end{array}$ & $\begin{array}{l}47 \text { years } \\
\text { F }\end{array}$ & hematuria & PTA & bladder & rejection & 1.5 months & $\begin{array}{l}\text { direct } \\
\text { closure }\end{array}$ \\
\hline Lee et al. [10] & $\begin{array}{l}30 \text { years } \\
\mathrm{F}\end{array}$ & hematuria & SPK & bladder & $\begin{array}{l}\text { cytomegalovirus } \\
\text { duodenitis }\end{array}$ & 2 months & $\begin{array}{l}\text { graft } \\
\text { pancreatectomy }\end{array}$ \\
\hline $\begin{array}{l}\text { Present } \\
\text { case }\end{array}$ & $\begin{array}{l}37 \text { years } \\
\mathrm{F}\end{array}$ & $\begin{array}{l}\text { abdominal } \\
\text { pain }\end{array}$ & SPK & enteric & $\begin{array}{l}\text { internal } \\
\text { hernia }\end{array}$ & 13 months & $\begin{array}{l}\text { graft } \\
\text { pancreatectomy }\end{array}$ \\
\hline
\end{tabular}

SPK = Simultaneous pancreas-kidney transplantation; PTA = pancreas transplantation alone.

Fig. 1. Abdominal computed tomography (CT) revealed a swollen pancreas graft by inflammatory (large white arrowhead) and severe dilatation of the total ileum. A large amount of intra-abdominal fluid had accumulated around the pancreas graft (small white arrowheads).

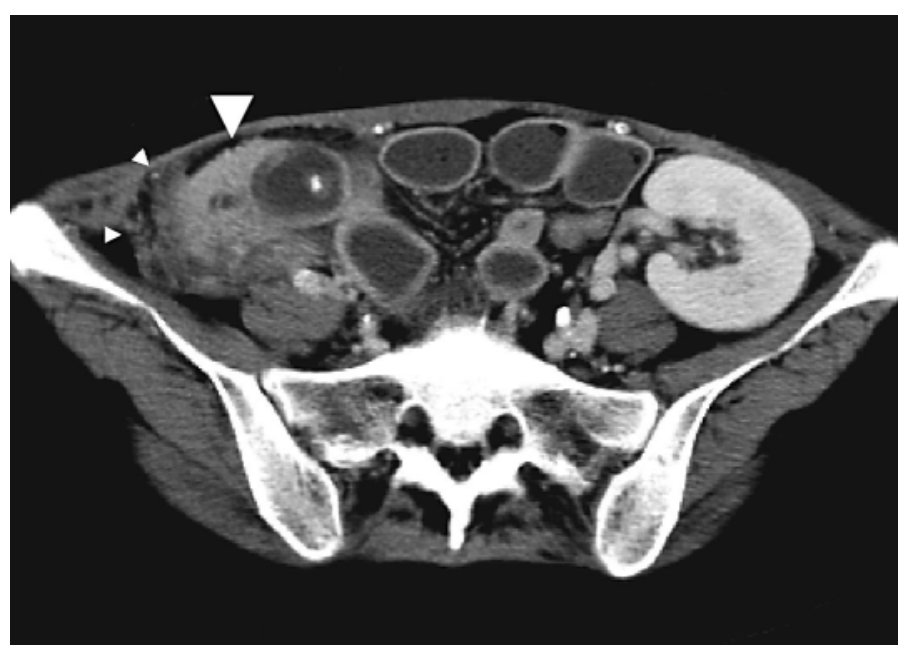


Fig. 2. Macroscopic findings for excised tissue: two holes are present on the suture line of the graft duodenum (white line). Mucosa of the graft duodenum macroscopically shows no ischemic change. The pancreas graft appears to be almost intact.

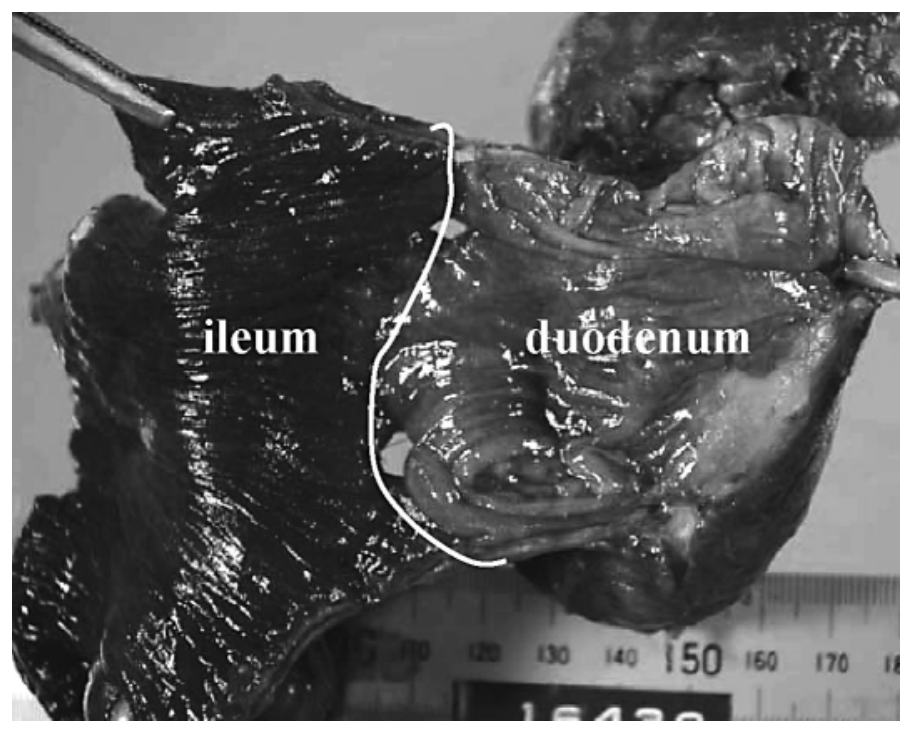




\section{References}

1 Sutherland DE, Kendall DM, Moudry KC, Navarro X, Kennedy WR, Ramsay RC: Pancreas transplantation in nonuremic, type I diabetic recipients. Surgery 1988;104:453-464.

-2 Gruessner RW, Dunn DL, Gruessner AC, Matas AJ, Najarian JS, Sutherland DE: Recipient risk factors have an impact on technical failure and patient and graft survival rates in bladder-drained pancreas transplants. Transplantation 1994;57:1598-1606.

-3 Gruessner RW, Sutherland DE, Troppmann C, Benedetti E, Hakim N, Dunn DL: The surgical risk of pancreas transplantation in the cyclosporine era: an overview. J Am Coll Surg 1997;185:128-143.

-4 Reddy KS, Stratta RJ, Shokouh-Amiri MH, Alloway R, Egidi MF, Gaber AO: Surgical complications after pancreas transplantation with portal-enteric drainage. J Am Coll Surg 1999;189:305-313.

-5 Colling C, Stevens RB, Lyden E, Lane J, Mack-Shipman L, Wrenshall L: Greater early pancreas graft loss in women compared with men after simultaneous pancreas-kidney transplantation. Clin Transplant 2005;19:158-161.

6 Gruessner RW, Manivel C, Dunn DL, Sutherland DE: Pancreaticoduodenal transplantation with enteric drainage following native total pancreatectomy for chronic pancreatitis: a case report. Pancreas 1991;6:479-488.

7 Schleibner S, Theodorakis J, Illner WD, Leitl F, Abendroth D, Land W: Ulcer perforation in the grafted duodenal segment following pancreatic transplantation - a case report. Transplant Proc 1992;24:827.

-8 Stephanian E, Gruessner RW, Brayman KL, Gores P, Dunn DL, Najarian JS: Conversion of exocrine secretions from bladder to enteric drainage in recipients of whole pancreticoduodenal transplants. Ann Surg 1992;216:663-672.

-9 Esterl RM, Stratta JR, Taylor RJ, Radio SJ: Rejection with duodenal rupture after solitary pancreas transplantation: an unusual cause of severe hematuria. Clin Transplant 1995;9:155-159.

10 Lee HK, Chung DH, Jung J, Kim SC, Han DJ, Kang KH: Three cases of pancreas allograft dysfunction. J Korean Med Sci 2000;15:105-110. 